\title{
Fidelity of DNA replication-a matter of proofreading
}

\author{
Anna Bębenek ${ }^{1}$ (I) Izabela Ziuzia-Graczyk ${ }^{1}$ \\ Received: 9 February 2018 / Revised: 27 February 2018 / Accepted: 28 February 2018 / Published online: 2 March 2018 \\ (c) The Author(s) 2018. This article is an open access publication
}

\begin{abstract}
DNA that is transmitted to daughter cells must be accurately duplicated to maintain genetic integrity and to promote genetic continuity. A major function of replicative DNA polymerases is to replicate DNA with the very high accuracy. The fidelity of DNA replication relies on nucleotide selectivity of replicative DNA polymerase, exonucleolytic proofreading, and postreplicative DNA mismatch repair (MMR). Proofreading activity that assists most of the replicative polymerases is responsible for removal of incorrectly incorporated nucleotides from the primer terminus before further primer extension. It is estimated that proofreading improves the fidelity by a $2-3$ orders of magnitude. The primer with the incorrect terminal nucleotide has to be moved to exonuclease active site, and after removal of the wrong nucleotide must be transferred back to polymerase active site. The mechanism that allows the transfer of the primer between pol and exo site is not well understood. While defects in MMR are well known to be linked with increased cancer incidence only recently, the replicative polymerases that have alterations in the exonuclease domain have been associated with some sporadic and hereditary human cancers. In this review, we would like to emphasize the importance of proofreading ( $3^{\prime}-5^{\prime}$ exonuclease activity) in the fidelity of DNA replication and to highlight what is known about switching from polymerase to exonuclease active site.
\end{abstract}

Keywords Replicative polymerases $\cdot 33^{\prime}-5$ ' proofreading $\cdot$ Polymerase structure $\cdot$ Fidelity

\section{Introduction}

Maintaining a low mutation rate is essential for cell viability and health. It was estimated that both in prokaryotic and eukaryotic cells, DNA is replicated with the very high fidelity with one wrong nucleotide incorporated once per $10^{8}-10^{10}$ nucleotides polymerized. The accuracy of replication relies heavily on the ability of replicative DNA polymerases to efficiently select correct nucleotides for the polymerization reaction and excise mistakenly incorporated nucleotides using their intrinsic exonucleases. DNA replication is constantly challenged by endogenous and exogenous chemicals, non-canonical DNA structures, and difficult to replicate DNA sequences. Both prokaryotic and eukaryotic cells possess a variety of specialized DNA polymerases that help to overcome replication blocks and that are

Communicated by M. Kupiec.

Anna Bębenek

aniab@ibb.waw.pl

1 Institute of Biochemistry and Biophysics, Polish Academy of Sciences, Pawińskiego 5a, 02-106 Warsaw, Poland subsequently recruited to DNA by PCNA modifications ( $\mathrm{Li}$ et al. 2017; Zhao and Washington 2017).

Eukaryotic cells are known to contain at least 16 different DNA polymerases while prokaryotic cells like an Escherichia coli have five different DNA polymerases (Goodman and Tippin 2000; Kunkel 2009). All known polymerases are divided into six families, $\mathrm{A}, \mathrm{B}, \mathrm{C}, \mathrm{D}, \mathrm{X}$, and $\mathrm{Y}$, on the basis of their sequence conservation (Bebenek and Kunkel 2004; Kunkel 2009). Recently, 17 human DNA polymerases have been purified and biochemically characterized an AEP (archaeo-eukaryotic primase) superfamily (Rudd et al. 2014).

Genomic DNA replication is normally carried out by the polymerases from A, B, C, or D families with high fidelity and processivity. Others, known as specialized, bypass, or translesion polymerases, participate in various DNA transactions related to repair, genome stability, and the generation of antibody diversity (Kunkel 2009; Shcherbakova et al. 2003a; Sweasy et al. 2006; Zhao and Washington 2017).

Replicative polymerases are also present in bacteriophages. The best characterized are B family polymerases from bacteriophages T4 and RB69, and A family polymerase 
from T7 bacteriophage (Johnson 2010; Karam and Konigsberg 2000).

In eukaryotic cells, replication of genomic DNA requires minimally three DNA polymerases, polymerase $\alpha, \delta, \varepsilon$ all from B family (Burgers and Kunkel 2017; Johansson and Macneill 2010; Makarova and Burgers 2015; Pellegrini 2012; Tahirov 2012), and polymerase $\gamma$ from A family that is responsible for mitochondrial DNA replication (Copeland 2010). The fourth polymerase that operates at replication fork is polymerase $\zeta$ also from B family, but this polymerase does not carry a bulk of DNA replication. Its role is critical at the difficult templates sites or when replicative DNA pols are compromised. Four subunits $\mathrm{Pol} \zeta$ is less accurate than other members of B family and does not have a proofreading activity (Makarova and Burgers 2015; Szwajczak et al. 2017). In the E. coli, genomic DNA replication is carried out by polymerase III (C family), Pol II (B family), and Pol I (A family) and the archaea genomes are replicated by the polymerases from D and B families (Banach-Orlowska et al. 2005; Cann and Ishino 1999; Edgell and Doolittle 1997; Kornberg and Baker 1992).

The replicative polymerase of E. coli, DNA polymerase III, is a ten subunit complex that is categorized into three major components; the Pol III core, the $\beta$-clamp, and the $\gamma$-complex. The Pol III core is a heterotrimer composed of the $\alpha$ polymerase, $\varepsilon 3^{\prime}-5^{\prime}$ proofreading exonuclease, and $\theta$ subunit of an unknown function (Johnson and O'Donnell 2005). The eukaryotic replicative polymerases are also multiple subunits holoenzymes. Polymerase $\alpha$ is comprised of a catalytic subunit p180 and an accessory subunit p70, and is a part of a four subunit pol-prim DNA primosome (MuziFalconi et al. 2003). The human DNA pol $\delta$ is heterotetrameric complex, consisting of the catalytic subunit p125 (POLD1) and three accessory subunits p50 (POLD2), p68 (POLD3), and p12 (POLD4) (Tahirov 2012). The Saccharomyces cerevisiae pol $\delta$ is a three-subunit complex consisting of a catalytic Pol3p subunit and two accessory subunits Pol31p and Pol32p subunit (Tahirov 2012). DNA pol $\varepsilon$ is composed of the catalytic subunit Pol2 (POLE) and three non-catalytic subunits Dpb2 (POLE2), Dpb3 (POLE3), and Dpb4 (POLE4) (Hogg and Johansson 2012).

\section{Replication fidelity}

Replicative polymerases achieve high fidelity of DNA replication by employing several mechanisms: (1) sensing proper geometry of correct base pair, (2) slowing down catalysis in case of a mismatch, and (3) partitioning the mismatched primer to exonuclease active site.

Polymerase selectivity is the prime determinant of fidelity. It is estimated that polymerases make errors approximately once every $10^{4}-10^{5}$ nucleotide polymerized (Echols and Goodman 1991; Showalter and Tsai 2002). Proofreading enhances the overall fidelity of DNA synthesis by a factor $10^{2}-10^{3}$ depending on the specific DNA polymerase and the nature of the primer terminal mispair (Kunkel 2009; Kunkel and Burgers 2008; McCulloch and Kunkel 2008; St Charles et al. 2015).

Structural studies of replicative DNA polymerase families showed that polymerase (pol) and 3'-5' exonuclease (exo) activities reside on one polypeptide. The exceptions are eukaryotic polymerases $\alpha$ and $\zeta$, that do not have functional exonuclease activity (Abbotts and Loeb 1985; Makarova and Burgers 2015), and polymerase III from E. coli, where exonuclease activity is carried out on different subunit $(\varepsilon$ subunit) encoded by a dnaQ gene (Maki and Kornberg 1987; Scheuermann and Echols 1984).

\section{B- family polymerase structures}

T4 DNA polymerase, a product of phage gene gp43, was the most intensely studied polymerase from B family and for many years served as a key model of replicative polymerase (Karam and Konigsberg 2000). The intact T4 DNA polymerase has never been crystallized, but fortunately, the polymerase of the related bacteriophage RB69 in apo conformation was crystallized by Steitz group in 1997 (Wang et al. 1997). Subsequently, the structures of ternary complexes of RB69 pol that contained a correct incoming dNTP and a dideoxy-terminated primer/ template with a resolution of $2.6 \AA$ and later at $1.8 \AA$ were reported (Franklin et al. 2001; Wang et al. 2011). For many years, RB69 DNA polymerase became a prototype DNA polymerase that enabled structure fidelity studies for this class of polymerase. As a result of these intensive studies, nearly 170 independently observed structures of RB69 DNA polymerase have been deposited in the Protein Data Bank (PDB) (Ren 2016). RB69 DNA polymerase like T4 DNA polymerase is a processive and high fidelity enzyme responsible for coordinated replication of both leading and lagging DNA strands. Recently crystal structures for catalytic subunits of eukaryotic replicative polymerase $\delta, \varepsilon$, and $\alpha$ have been obtained (Hogg et al. 2014; Perera et al. 2013; Swan et al. 2009).

Despite the amino-sequence differences, all replicative polymerase structures share a common overall architecture and are composed of five subdomains: $\mathrm{N}$-terminal domain (NTD), exonuclease domain (exo), and polymerase domain (pol), the core of the enzyme. The polymerase domain contains a palm domain with several of the catalytic residues, a finger domain with most of the side chains that bind the incoming dNTP, and a thumb domain that binds primer-duplex DNA. The exonuclease domain carries a $3^{\prime}-5^{\prime}$ proofreading activity that removes misincorporated nucleotides. The function of the $\mathrm{N}$-terminal 
domain is not well defined. In RB69 and T4 polymerases, the NTD domain binds its messenger RNA and represses translation (Petrov et al. 2002). It was also shown that NTD could play a role in polymerase stability and fidelity through the interaction with the fingers domain ( $\mathrm{Li}$ et al. 2010; Prindle et al. 2013). Pol $\delta$ NTD domain contains three motifs. One of these motifs has the structure and topology resembling an OB-fold which may be involved in single-stranded DNA binding. Other motifs contain an RNA-binding motif (RRM) that may be involved in RNA binding (Swan et al. 2009).

\section{A family polymerase structure}

The pol A family polymerases, also known as the pol I family, have two separate enzymatic activities as well, a 5'-3' polymerase activity and a $3^{\prime}-5^{\prime}$ exonuclease activity on the same peptide (Klenow fragment). The polymerase domain of DNA pol I family resembles in overall the topology of the B family polymerase domain with fingers that bind an incoming nucleotide and interact with ssDNA, palm, which harbors catalytic residues, and thumb domain which binds ds DNA (Patel et al. 2001; Steitz 1999). The structures of the fingers and thumb domains are unique in $\mathrm{A}$ and $\mathrm{B}$ families. The palm domain structure shares the
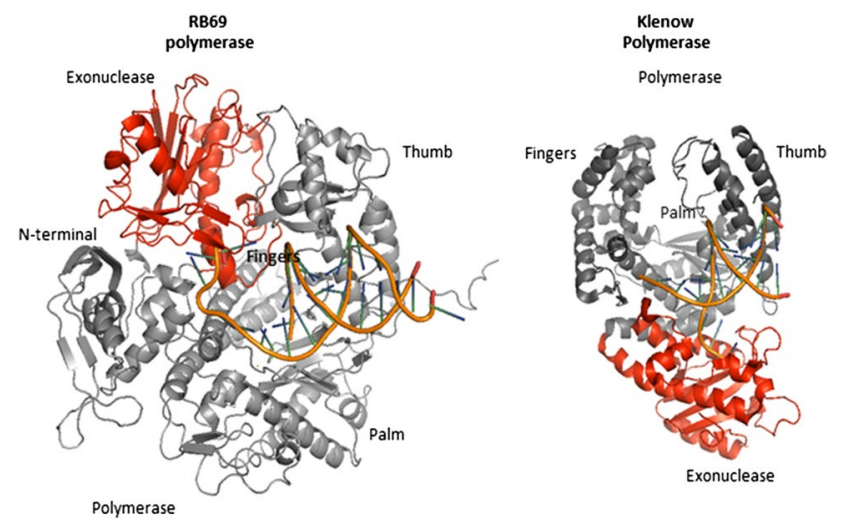

Fig. 1 Position of the exonuclease and polymerase active sites in A family (Klenow polymerase) and B family (RB69 polymerase). The enzymes are in cartoon representation with the polymerase domain in grey and exonuclease domain in red and DNA in orange. The images were generated using PyMol (DeLano 2002), and are based on the crystal structure of Klenow in the complex with DNA (PDB ID code $1 \mathrm{KLN}$ ) and the ternary complex structure of RB69 polymerase (PDB ID code $3 \mathrm{NCI}$ )

same fold in A and B family. The exonuclease domain is distal to the palm domain (Fig. 1) a location much different compared to B family (Kunkel and Bebenek 2000).

\section{C family polymerase structure}

Like all polymerases, E. coli Pol III $\alpha$ contains finger, thumb, and palm domains. In contrast to A and B family, the palm domain structure of Pol III has the basic fold of Pol $\beta$ like nucleotidyltransferase superfamily (X family). The palm domain contains three conserved catalytic aspartates that bind the catalytic magnesium ions and utilize the same twometal ion catalytic mechanism as other polymerases (Lamers et al. 2006). Pol III has an additional domain PHP domain. PHP domain of Pol III has been proposed to act as a pyrophosphatase that hydrolyzes the pyrophosphate by-product of DNA synthesis (Aravind and Koonin 1998; Lamers et al. 2006). PHP domain from Thermus aquaticus Pol III was shown to have a $3^{\prime}-5^{\prime}$ exonuclease that is $\mathrm{Zn}^{2+}$ dependent and may act as a second exonuclease (Stano et al. 2006). The proofreading domain is carried on a separate polypeptide $($ dna $Q)$ but is tightly associated with polymerase during DNA replication (Scheuermann and Echols 1984; Toste Rêgo et al. 2013).

\section{Polymerase active site}

A detailed examination of the binary and ternary complex crystal structures of the pol I family of DNA polymerases has revealed that template-primer binding is associated with translational and rotational changes in the thumb subdomain, described as "clamping down" over DNA. Subsequently, dNTP binding induces movement in the fingers domain (mainly O-helix) by $\sim 41^{\circ}$, which in turn forms the "closed" ternary complex (Beese et al. 1993).

The crystal structure of an RB69 gp43 ternary complex showed that binding of dNTP induces conformational changes in the polymerase from an open state in the absence of nucleotide to the closed state with the nucleotide. After binding of dNTP to the template primer, the fingers rotate about $60^{\circ}$ towards the palm domain, bringing conserved residues from motif B closer to palm catalytic residues (Fig. 2). The palm subdomain harbors the catalytic core responsible for pol activity. Two highly conserved acidic residues (D411 and D623) serve as ligands for metal ions A and B, which are crucial for catalyzing the nucleotidyl transfer reaction. Two-metal $\mathrm{Mg}^{2+}$ ions are required to coordinate transition state in the nucleotide transfer reaction and assist in the departure of the PPi product (Xia and Konigsberg 2014). This two-metal requirement for catalysis seems to be general for all polymerases (Johnson 2010). However, recently, the possibility that a third metal ion can be involved in the catalysis of pol $\beta$ and coordinate the PPi departure was postulated by (Yang et al. 2016).

Fingers' domain contains a conserved dNTP-binding motif KX3NSXTG. Each phosphate group of the incoming dNTP is coordinated to a protein side chain. Both fingers and 


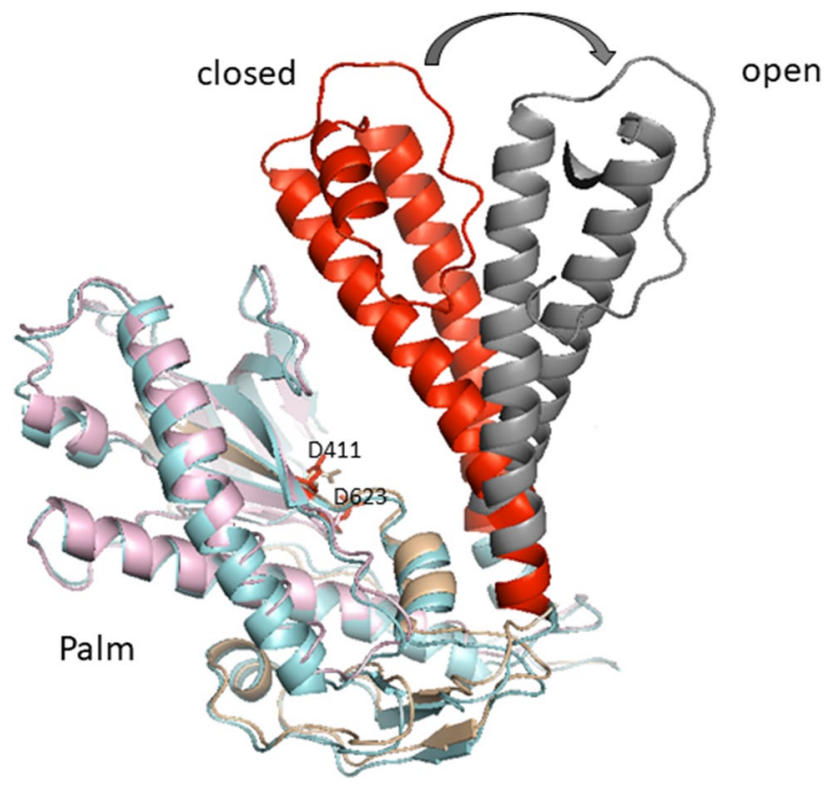

Fig. 2 Movement of fingers domain from the "closed" to "open" conformation in RB69 DNA polymerase. Fingers' movements brings conserved residues from motif B closer to palm catalytic residues D411 and D623 creating polymerase active site. The image was created using PyMol (DeLano 2002) and the ternary complex structure of RB69 polymerase (PDB ID code 3NCI)

palm domain form a tight-binding pocket around the nascent base pair. The geometry of this pocket accommodates only a correct base pair with proper Watson-Crick geometry. The proper alignment of the incoming nucleotide with the templating nucleotide promotes catalysis and extension. Following the insertion of a correct nucleotide, polymerase must translocate to allow binding of the next nucleotide. If the mismatched nucleotide is bound, catalysis is slowed, and primer terminus is directed to the exonuclease active site (Xia and Konigsberg 2014).

Structural analysis of the related B family polymerases also revealed conformational changes after nucleotide binding from an open to closed state. Thus, finger "open" to "close" state during polymerization is a universal mechanism for all polymerases.

\section{The exonuclease active site}

In all B family of DNA, Pols exonuclease contains three conserved motifs, Exo I, Exo II, and Exo III. Exonuclease active site, like the polymerase active site, contains essential aspartate residues that bind the two $\mathrm{Mg}^{+}$ions that are required for the hydrolysis reaction via a two-metal mechanism (Bernad et al. 1989).

The exonuclease (exo) subdomain lies between the N-terminal and thumb subdomains. In RB69 polymerase, the exoand-pol active sites are separated by about $30-40 \AA$. When an incorrect dNTP is incorporated onto the $3^{\prime}$ terminus of the primer strand, the pol helps to switch the primer terminus from the pol to the exo site, facilitating cleavage of the 3 '-terminal nucleotide residue. To reach exo active site, primer strand has to separate from the template along three nucleotides to place the primer 3'-end in the exonuclease active site for editing (Shamoo and Steitz 1999). DNA polymerases with proofreading ability can sense misincorporated nucleotides by contacting the minor groove of base pairs beyond the insertion site. The polymerase senses the geometry of the base pair through specific hydrogen bond acceptors at the pyrimidine $\mathrm{O}-2$ and purine $\mathrm{N}-3$ atoms. This geometry is lost when the mismatches are present. RB69 DNA polymerase can sense the mismatches up to the two base pairs post the insertion site (Wang et al. 2011). These contacts are much more extensive in eukaryotic pol $\delta$ and extend to five base pairs (Doublie and Zahn 2014; Swan et al. 2009). In Pol A family, the active sites for the polymerase and exonuclease domains are also located in separate structural domains and are separated by about $30 \AA$ in Klenow fragment and $35 \AA$ in T7 pol (Beese et al. 1993; Ollis et al. 1985). The primer must melt the last four base pairs at the 3' terminus of a duplex DNA to reach exonuclease active site (Lam et al. 1998). The $3^{\prime}-5$ ' exonuclease domains are located on opposite sides of the pol active sites (Fig. 1) what causes differences in the coordination between the two active sites among B- and A family enzymes (Kunkel and Bebenek 2000).

In B family, the partitioning of the DNA primer between the polymerase and exonuclease active site is accompanied by the $\beta$-hairpin loop, a part of the exonuclease domain. In RB69 DNA polymerase, residues 251-262 form an extended hairpin loop ( $\beta$-hairpin). In the editing mode, both DNA strands depart from the polymerase active site and $\beta$-hairpin loop holds the template strand in place, while the primer strand partially separates from the template strand and passes behind the $\beta$-hairpin to reach the exonuclease active site (Hogg et al. 2007; Ren 2016; Shamoo and Steitz 1999). Mutating residues in the loop of the $\beta$ hairpin in T4 or RB69 DNA polymerases (G255S and G258S respectively) or deleting the loop of the $\beta$ hairpin caused a mutator phenotype (Hogg et al. 2007; Trzemecka et al. 2009). Biochemical analysis showed that the mutant polymerases degraded ssDNA with the same efficiency as wild-type enzymes but have decreased ability to degrade dsDNA, thus showing that $\beta$ hairpin loop is, indeed, essential in strand separation and does not affect exonuclease activity (Fig. 3) (Hogg et al. 2007; Subuddhi et al. 2008; Trzemecka et al. 2009). Almost all B family DNA polymerases whose structures have been solved to date show a similarly placed $\beta$-hairpin loop in the same orientation with respect to the polymerase and exonuclease active sites as in RB69 gp43. The $\beta$-hairpin is present in bacteriophage $\varphi 29$ (Salas et al. 2008), herpes simplex virus (Liu et al. 2006), the archaeal polymerases (Hashimoto 
A

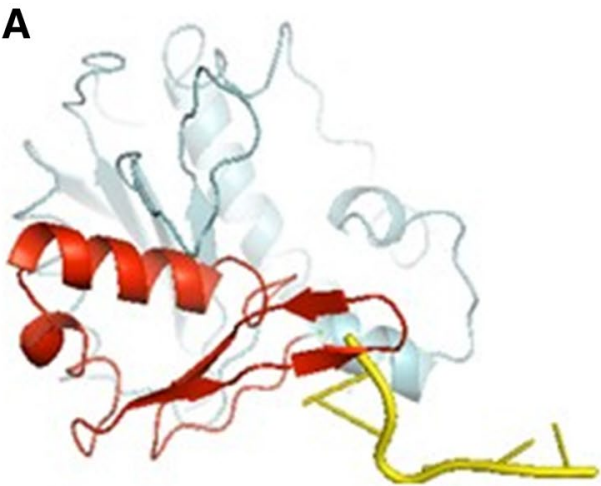

B

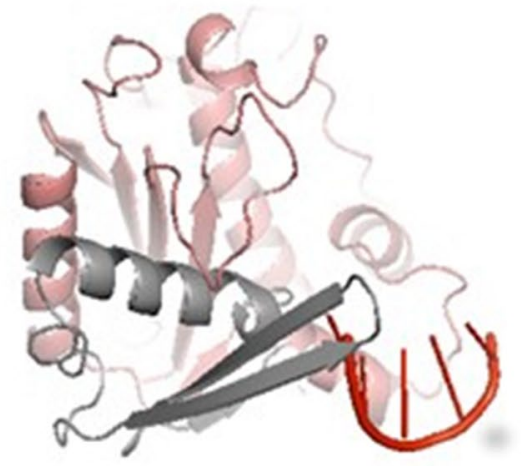

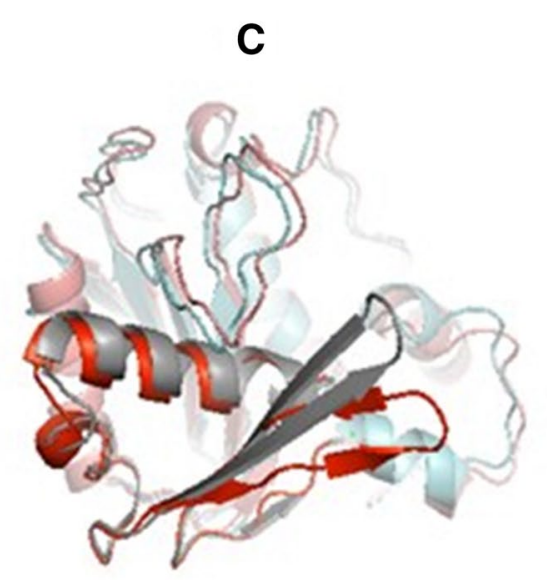

Fig. 3 Position of the $\beta$-hairpin loop in editing (a) and replicating (b) modes. Superposition of the two structures showing the movement of the $\beta$-hairpin loop (c). The images were generated using PyMol
(DeLano 2002) based on the ternary crystal structure of RB69 DNA polymerase (PDB ID code 3NCI) and editing structure (PDB ID 1CLQ)

stabilize polymerase complexes (Darmawan et al. 2015). The $\beta$-hairpin loop is truncated in pol $\varepsilon$, is too short to contact the DNA, and presumably is not involved in active site switch-
Table 1 Function of $\beta$-hairpin loop in B family polymerases

\begin{tabular}{|c|c|c|c|}
\hline Polymerase & $\beta$-hairpin loop & Role & Function \\
\hline T4 and RB69 & yes & $\begin{array}{l}\text { Strand separation and positioning } \\
\text { primer strand in exo site }\end{array}$ & Pol/exo coupling \\
\hline E. coli pol II & Yes & $\begin{array}{l}\text { Altered partitioning keeps the primer } \\
\text { near pol active site }\end{array}$ & Translesion synthesis \\
\hline Pol $\delta$ & Yes & Stabilize polymerase complexes & $\begin{array}{l}\text { Optimum DNA repli- } \\
\text { cation efficiency }\end{array}$ \\
\hline Pol $\varepsilon$ & Yes but truncated & Not involved in strand separation & None \\
\hline
\end{tabular}

et al. 2009). Although the $\beta$-hairpin loop is located in the same position within their exonuclease domain, not always play the same role as in RB69 gp43 and T4 gp43 (Table 1). DNA pol $\delta$ has similarly placed $\beta$-hairpin loop, but as it was demonstrated very recently, DNA pol $\delta$ does not need the hairpin for proofreading, but $\beta$-hairpin loop is required for optimum DNA replication efficiency, because its role is to ing (Ganai et al. 2015). Instead, Pol $\varepsilon$ has an additional large domain named the $\mathrm{P}$ domain that is built from insertions of residues 533-555 and 682-760 not previously observed in B family polymerases. The $\mathrm{P}$ domain is built of three $\beta$-strands, two $\alpha$-helices, and a $\beta$-hairpin loop. Together, these structural motifs form an elongated domain that extends outward from the palm domain toward dsDNA. P domain allows 
the interactions between the pol $\varepsilon$ and the duplex DNA and allows for sensing mismatches not only at the primer end but also at positions n-4 or n-5 that may destabilize the 3 '-terminus of the primer at the polymerase active site and lead to a transfer of primer terminus to the exonuclease active site. The $\mathrm{P}$ domain may be an obvious replacement of $\beta$-hairpin loop, because it can help to maintain close contact between the polymerase and DNA while switching active sites. It can compensate the lack of $\beta$-hairpin loop (Ganai et al. 2015; Hogg et al. 2014).

The E. coli Pol II that also participates in chromosomal DNA replication (Banach-Orlowska et al. 2005) has the 20 residue $\beta$ barrel insertion in the $\mathrm{N}$ domain that shifts the position of the $\beta$-hairpin loop and alters the partitioning between polymerization and proofreading by keeping the primer end near the polymerase active site far from the exonuclease (Wang and Yang 2009). Because of these differences in $\beta$ hairpin position, the Pol II can carry translesion synthesis past DNA lesion (Wang and Yang 2009).

\section{Pol-to-exo active site switching}

Polymerases that have an exonuclease domain in the same polypeptide with polymerase domain can proofread errors intramolecularly, without enzyme dissociation from the mismatch primer terminus (Joyce 1989) or intermolecularly with enzyme dissociation and rebinding to the DNA to form exonuclease complexes (Johnson 1993; Reha-Krantz 2010).

The joint structural analysis of all known RB69 DNA polymerase structures enabled to extract structural changes during translocation of the polymerase along a DNA template and processive switching between the polymerase and exonuclease active sites (Ren 2016). Translocation of the polymerase is associated with the fingers motion from the closed after dNTP hydrolysis and release of PPi to an open conformation. When the correct Watson-Crick base pair is formed, the thumb domain is disengaged from the minor groove of the duplex DNA which is accompanied by overall rotation of the $\mathrm{N}$-terminal and thumb domain around the DNA duplex and facilitates the relative sliding between protein and DNA. When the mismatch is formed, the thumb is constantly holding the duplex in the minor groove that avoids translocation and allows the primer to shuttle to and from the exonuclease active site. The thumb holds the DNA duplex in its minor groove with Lys734 and 800 (Ren 2016).

The intermolecular site switching which requires DNA polymerase dissociation was proposed for T4 DNA polymerase after it was observed that active T4 DNA polymerase exchange was taking place during T4 replisome replication in vitro (Yang et al. 2004). The T4 and RB69 DNA polymerases are not processive, and the processivity during replication is enhanced by the processivity factor, the product of gene $g p 45$ that forms a homotetrameric structure that encircles the DNA (Karam and Konigsberg 2000). Gp45 protein tether more than one T4 or RB69 polymerase and when the replicating polymerase dissociates from the mismatch primer end the same or another polymerase can rebind the mismatched DNA in the exonuclease active site (Yang et al. 2004). The intermolecular site switching can also operate for pol $\delta$ (Flood et al. 2015).

The intramolecular and intermolecular transfer of DNA between the pol and exo sites was recently also demonstrated for DNA polymerase I Klenow fragment by monitoring the movement of the DNA between these two active sites by a single-molecule Förster resonance energy transfer (smFRET) method (Lamichhane et al. 2013).

\section{Switching between polymerase and exonuclease active sites can be modulated by the interaction with the sliding clamp}

DNA sliding clamp assists most of the replicative polymerases in ensuring processive and accurate genome replication. Clamps despite their low level of sequence identity, from prokaryotes and eukaryotes, form a similar ring structure with a central hole that encircles duplex DNA. Polymerase interacts with PCNA by a small conserved PCNA-interacting protein motif (PIP-box). The PIP motif binds a hydrophobic patch on the PCNA surface. For archaeal DNA Pol B polymerase from Pyrococcus furiosus (Pfu Pol) based on computational analysis of all available structural information and molecular dynamics simulations, novel contacts were found between DNA polymerase and the PCNA subunits adjacent to PIP motif (Nishida et al. 2009; Xu et al. 2016). In the pol-mode, these interactions involve polymerase residue R706 (thumb domain) and residue E171 from PCNA1 subunit. In the exo-mode, interactions are made by a helix from palm domain that contains a patch of arginine residues (R379, R380, and R382) and a negatively charged loop on the PCNA2 subunit surface called the "switch hook" (Xu et al. 2016). It was proposed that the transition from the polymerase mode to exonuclease mode is executed by the rotation of the Pol core (palm, N-terminal, fingers, and exonuclease domain) around thumb domain that is stably bound to the clamp surface. It enforces a $56^{\circ}$ rotation of a palm domain and brings the palm arginine patch helix into contact with the negatively charged switch-hook loop of PCNA2 that locks the complex in the exo-mode conformation. These results provided that PCNA can coordinate the transition between the pol and exo states during DNA replication $(\mathrm{Xu}$ et al. 2016).

In E. coli, it was shown that Pol III $\alpha$ interaction with a clamp is enhanced by the exonuclease that provides a second indirect interaction to the clamp. By doing so, it enhances the interaction between Pol III $\alpha$ and a clamp and provides 
the exonuclease with more efficient access to the DNA. Exonuclease binds to the clamp by a canonical clamp binding motif that is positioned immediately after the exonuclease catalytic domain. Exonuclease clamp interactions are required for optimal proofreading activity (Fernandez-Leiro et al. 2015; Park et al. 2018; Toste Rêgo et al. 2013).

\section{Modulation of pol and exo activity by the subunit composition in pol $\delta$ holoenzyme}

The human pol $\delta$ is a heterotetramer consisting of the catalytic subunit p125 (POLD1) and three accessory subunits p50 (POLD2), p68 (POLD3), and p12 (POLD4) (Tahirov 2012). The p12 subunit is degraded in response to DNA damage converting Pol $\delta 4$ to Pol $\delta 3$. It was shown that Pol $\delta 3$ is less error prone due to greater proofreading ability and greater discrimination against mismatched primers and small lesions that are readily bypassed in a mutagenic manner by Polס4 (Lee et al. 2017; Zhang et al. 2016).

\section{Proofreading in trans}

The eukaryotic genome is replicated by three replicative polymerases, the pol $\alpha$, pol $\delta$, and pol $\varepsilon$. Polymerase $\alpha$ is responsible for the synthesis of the 20-30 nucleotides during Okazaki fragment initiation, that is further extended by lagging strand polymerase $\delta$ (Kunkel 2009; Kunkel et al. 1989). The fidelity of DNA pol $\alpha$ is low as this polymerase lacks its own proofreading (Kunkel et al. 1989). It is estimated that polymerase $\alpha$ contributes to the synthesis of about $1.5 \%$ of the eukaryotic genome, and with calculated base substitution error rate of $10^{-4}$, this polymerase would introduce many thousands of mismatches during each round of replication. It was shown that errors introduced by polymerase $\alpha$ are removed by the exonucleolytic proofreading of polymerase $\delta$ (Pavlov et al. 2006). Later, it was also demonstrated that polymerase $\delta$ could proofread errors introduced by polymerase $\varepsilon$ acting in trans on the leading DNA strand, but polymerase $\varepsilon$ was unable to correct Pol $\delta$-dependent replication errors as well as errors made by Pol $\alpha$. In addition, errors created by proofreading defective polymerase $\varepsilon$ cannot be corrected by wild-type Pol $\varepsilon$ polymerase (Flood et al. 2015; Pavlov et al. 2006).

\section{External 3'-5' exonucleases}

A number of DNA pol-unassociated 3'-5' exonuclease have been identified in eukaryotic cells (Mason and Cox 2012). Some of these exonucleases have been observed to have the ability to remove $3^{\prime}$ mismatched termini from doublestranded DNA and thus to correct replication errors. Werner protein (WRN) belongs to the RecQ family of helicases (Gray et al. 1997). WRN encodes a 3'-5' helicase and also a
3'-5' exonuclease (Kamath-Loeb et al. 1998). It was shown that polymerase delta proofreading could be enhanced by the Werner protein. It was presented that WRN was able to proofread for Pol $\delta$ by removing 3 '-terminal mismatches to enable primer extension by Pol $\delta$. Consistent with this in vitro observations, it was demonstrated that WRN contributes to the maintenance of DNA synthesis fidelity in vivo. Cells expressing limiting amounts ( 10\% of normal) of WRN have elevated mutation frequencies compared with wild-type cells (Kamath-Loeb et al. 2012).

The tumor suppressor protein p53 also possess $3^{\prime}-5^{\prime}$ exonuclease activity (Mummenbrauer et al. 1996) and can remove mismatches from replicating DNA strand (Huang 1998). It was shown in vitro that $\mathrm{p} 53$ protein enhances the replication fidelity of error-prone polymerase $\alpha$ (Hollstein et al. 1996). Later, it was demonstrated that polymerase $\alpha$-primase (prim-pol) could form a complex with p53 in vivo. The purified prim-pol/p53 complex in vitro showed both exonuclease and polymerase activity (Melle and Nasheuer 2002) and was able to extend a mismatched DNA primer terminus. These data provided evidence that p53 can correct DNA replication error introduced by pol $\alpha$.

\section{Contribution of proofreading to fidelity}

The proofreading on average improves replication fidelity by about $10-1000$-fold. The errors that escape proofreading are repaired later by the mismatch repair (MMR) (Kunkel 2009; McCulloch and Kunkel 2008). The contribution of the proofreading or the mismatch repair system can be directly measured in vivo by comparing spontaneous mutation rates in wild strain or in the strains that are defective in one of the correction pathways or both. Different types of errors are produced by the polymerase. The most common mistakes are base substitution errors. There are two types of base substitution errors, transitions (purine-purine and pyrimidine-pyrimidine mismatches) and transversions (purine-pyrimidine mismatches). The base substitution errors depend on the selectivity of the polymerase. Polymerase active site can bind some forms of these mispairs as they can adopt wobble conformation or exist in a rare tautomeric form (Goodman et al. 1993; Kunkel and Bebenek 2000). From the in vivo and in vitro fidelity measurements, it became evident that the transition mismatches are less efficiently proofread than transversion mismatches and are more easily extended by the polymerases. This unbiased preference for transition mismatches is corrected by mismatch repair system that discriminates more efficiently against transitions that transversions which at the end results at the same low level of both types of errors (Schaaper 1993). Another type of mutations that are introduced by replicative polymerases is frameshift mutations both deletion 
and addition errors (indels), especially in mononucleotide microsatellites. Microsatellites are tandem repeats of 1-6 base pairs per repeat unit that are found in all organisms, at varying abundance (Baptiste et al. 2015; Bebenek and Kunkel 2000; Kunkel and Bebenek 2000). The primer-template slippage during replication of repetitive sequences produces misaligned intermediates that are stabilized by a correct base and subsequent polymerization leads to deletion if the flipped nucleotide is in the template strand or to addition if the flipped nucleotide is in the primer strand (reviewed in Bebenek and Kunkel 2000). Frameshift mutations can also be generated at noniterated or short repetitive sequences. Proofreading can remove indel mutations in a short repetitive sequence and noniterated sequences with almost the same efficiency as base substitution mutations but is much less efficient in removing frameshift mutations in homopolymeric runs. These mutations are removed efficiently by mismatch repair system (Kunkel and Bebenek 2000; Yamamoto and Imai 2015). Instability of the microsatellite sequences is associated with many disease states including cancer (Yamamoto and Imai 2015).

\section{Replicative polymerases in cancer}

Studies in the model organisms have confirmed the essential role of DNA polymerase proofreading in the maintenance of genomic stability. Exonuclease-deficient mutants of Pol $\delta$ or Pol $\varepsilon$ containing alanine substitution at catalytic aspartate residue in $S$. cerevisiae show a $10-100$-fold increase in mutation rates (Morrison et al. 1993; Pavlov et al. 2001; Shcherbakova et al. 2003b). In the mice model, when the exonuclease domain of Pol $\delta$ (encoded by the POLDl gene) or Pol $\varepsilon$ (encoded by the POLE gene) was inactivated by mutation at exonuclease, catalytic residue elevated base substitution mutation rates, and increased incidence of cancers was observed. The type of cancers was different for each polymerase mutant. Pol $\delta$ exo- mice developed lymphomas and carcinomas of the skin and lung, whereas Pol $\varepsilon$ exo- mice developed intestinal tumors (Albertson et al. 2009; Goldsby et al. 2002, 2001). Interestingly, cancers only developed in mice homozygous for proofreading deficient polDl and polE alleles and in mismatch proficient background (Goldsby et al. 2002). That was the first such example showing that mutations in genes encoding polymerases could be a source for multiple mutations that if accumulated over the lifetime can increase the risk of cancer.

In 2012, The Cancer Genome Atlas (TCGA) (Network 2012) published the results of analysis of exome sequencing of 224 sporadic colorectal carcinomas (CRC). These study revealed that a subset of ultramutated but microsatellite stable (MSS) CRC tumors with the highest mutational load had alterations in POLE gene. POLE alterations were also found in hypermutated sporadic endometrial tumors (Church et al. 2013).

The changes were found within and close to the Exo motifs required for exonuclease activity, suggesting that inactivation of exonuclease activity was responsible for the hypermutator phenotype (Rayner et al. 2016). The hypermutator phenotype observed in POLE proofreading domain mutant is characterized by an excess of substitution mutations, in particular, a relative excess of $\mathrm{G}: \mathrm{C} \rightarrow \mathrm{T}: \mathrm{A}$ transversions (Alexandrov et al. 2013). The most common POLE variant is the replacement of the proline 286 by either the arginine or histidine. The functional consequences of P286R mutation were studied using a yeast homolog pol2-P301R mutant. The corresponding P301R change in yeast Pol $\varepsilon$ conferred an exceptionally strong mutator phenotype greatly exceeding that of any previously characterized Pol $\varepsilon$ mutant, including proofreading-deficient mutants. It was also shown that heterozygosity for the P301R also produced a strong mutator effect comparable with that of MMR deficiency, the effect not observed for proofreading-deficient pol2 exopolymerase (Kane and Shcherbakova 2014).

Only two cases of possibly pathogenic somatic POLDI variation have been identified to date (Shlien et al. 2015).

In addition, germline mutations affecting the exonuclease domains of POLE and POLD1 were found to cause a highpenetrance hereditary colorectal cancer and endometrial cancer predispositions (Bellido et al. 2016). These discoveries strongly suggested that loss of proofreading activity of replicative DNA polymerases is the initiating cause of some hereditary and sporadic human cancers.

The role of proofreading domain mutations in cancer has been recently extensively reviewed (Barbari and Shcherbakova 2017; Rayner et al. 2016).

\section{Concluding remarks}

Replicative polymerases use several mechanisms to achieve high and accurate DNA replication. Proofreading plays an essential role in this process. Proofreading activity either is associated with the polymerase or carried on a separate subunit, but in any case, it is estimated that proofreading improves replication fidelity by a factor of $10^{2}-10^{3}$. Recent studies with eukaryotic replicative polymerases that have been found in some cancers showed that mutations in exonuclease domain close to catalytic residues could cause much stronger mutator phenotype exceeding the previously observed for exo-deficient polymerases (Kane and Shcherbakova 2014). A mechanism that would explain such high level of mutagenesis is not known.

The interplay between the pol and exo activity may be modulated by the interaction with one of the accessory proteins that accompany polymerase during DNA replication, 
like interactions with $\beta$ sliding clamp and $\varepsilon$ subunit in $E$. coli replisome (Park et al. 2018; Xu et al. 2016). It was shown that mutations in a non-catalytic subunit of Pol $\varepsilon, \mathrm{Dpb} 2$, that destabilize interactions with Psf1 and Psf3 subunits in GINS complex result in increased spontaneous mutagenesis in yeast S. cerevisiae (Dmowski and Fijałkowska 2017; Garbacz et al. 2015). One can speculate that mutations in the exonuclease domain that does not affect catalytic site may affect primer terminus site switching between pol and exo site, sending more often uncorrected primer back to polymerases active site or not allowing the primer terminus to reach the exo active site. Many other scenarios can take place, and it is a long way to fully understand the mechanism that is responsible for the coordinated action of polymerase and exonuclease activity. Finally, it can be assumed that the proofreading may participate too much higher extent in replication fidelity that it was previously anticipated.

Acknowledgements We would like to thank Iwona Fijałkowska and Karolina Makieła-Dzbeńska for careful and critical reading and their thoughtful suggestions on the article.

Open Access This article is distributed under the terms of the Creative Commons Attribution 4.0 International License (http://creativeco mmons.org/licenses/by/4.0/), which permits unrestricted use, distribution, and reproduction in any medium, provided you give appropriate credit to the original author(s) and the source, provide a link to the Creative Commons license, and indicate if changes were made.

\section{References}

Abbotts J, Loeb LA (1985) DNA polymerase alpha and models for proofreading. Nucleic Acids Res 13:261-274 doi

Albertson TM, Ogawa M, Bugni JM, Hays LE, Chen Y, Wang YP, Treuting PM, Heddle JA, Goldsby RE, Preston BD (2009) DNA polymerase epsilon and delta proofreading suppress discrete mutator and cancer phenotypes in mice. Proc Natl Acad Sci USA 106:17101-17104. https://doi.org/10.1073/pnas.0907147106

Alexandrov LB, Nik-Zainal S, Wedge DC, Aparicio SA, Behjati S, Biankin AV, Bignell GR, Bolli N, Borg A, Børresen-Dale AL, Boyault S, Burkhardt B, Butler AP, Caldas C, Davies HR, Desmedt C, Eils R, Eyfjörd JE, Foekens JA, Greaves M, Hosoda F, Hutter B, Ilicic T, Imbeaud S, Imielinski M, Imielinsk M, Jäger N, Jones DT, Jones D, Knappskog S, Kool M, Lakhani SR, López-Otín C, Martin S, Munshi NC, Nakamura H, Northcott PA, Pajic M, Papaemmanuil E, Paradiso A, Pearson JV, Puente XS, Raine K, Ramakrishna M, Richardson AL, Richter J, Rosenstiel P, Schlesner M, Schumacher TN, Span PN, Teague JW, Totoki Y, Tutt AN, Valdés-Mas R, van Buuren MM, van 't Veer L, Vincent-Salomon A, Waddell N, Yates LR, Zucman-Rossi J, Futreal PA, McDermott U, Lichter P, Meyerson M, Grimmond SM, Siebert R, Campo E, Shibata T, Pfister SM, Campbell PJ, Stratton MR, Initiative APCG., Consortium IBC, Consortium IM-S, PedBrain I (2013) Signatures of mutational processes in human cancer. Nature 500:415-421. https://doi.org/10.1038/ nature 12477
Aravind L, Koonin EV (1998) Phosphoesterase domains associated with DNA polymerases of diverse origins. Nucleic Acids Res 26:3746-3752 doi

Banach-Orlowska M, Fijalkowska IJ, Schaaper RM, Jonczyk P (2005) DNA polymerase II as a fidelity factor in chromosomal DNA synthesis in Escherichia coli. Mol Microbiol 58:61-70. https:// doi.org/10.1111/j.1365-2958.2005.04805.x

Baptiste BA, Jacob KD, Eckert KA (2015) Genetic evidence that both dNTP-stabilized and strand slippage mechanisms may dictate DNA polymerase errors within mononucleotide microsatellites. DNA Repair 29:91-100. https://doi.org/10.1016/j.dnare p.2015.02.016

Barbari SR, Shcherbakova PV (2017) Replicative DNA polymerase defects in human cancers: consequences, mechanisms, and implications for therapy. DNA Repair 56:16-25. https://doi. org/10.1016/j.dnarep.2017.06.003

Bebenek K, Kunkel TA (2000) Streisinger revisited: DNA synthesis errors mediated by substrate misalignments. Cold Spring Harb Symp Quant Biol 65:81-91

Bebenek K, Kunkel TA (2004) Functions of DNA polymerases. Adv Protein Chem 69:137-165. https://doi.org/10.1016/S0065 -3233(04)69005-X

Beese LS, Derbyshire V, Steitz TA (1993) Structure of DNA polymerase I Klenow fragment bound to duplex DNA. Science 260:352-355 doi

Bellido F, Pineda M, Aiza G, Valdes-Mas R, Navarro M, Puente DA, Pons T, Gonzalez S, Iglesias S, Darder E, Pinol V, Soto JL, Valencia A, Blanco I, Urioste M, Brunet J, Lazaro C, Capella G, Puente XS, Valle L (2016) POLE and POLD1 mutations in 529 kindred with familial colorectal cancer and/or polyposis: review of reported cases and recommendations for genetic testing and surveillance. Genet Med 18:325-332. https://doi.org/10.1038/ $\operatorname{gim} .2015 .75$

Bernad A, Blanco L, Lázaro JM, Martín G, Salas M (1989) A conserved 3'-5' exonuclease active site in prokaryotic and eukaryotic DNA polymerases. Cell 59:219-228 doi

Burgers PMJ, Kunkel TA (2017) Eukaryotic DNA replication fork. Annu Rev Biochem 86:417-438. https://doi.org/10.1146/annur ev-biochem-061516-044709

Cann IK, Ishino Y (1999) Archaeal DNA replication: identifying the pieces to solve a puzzle. Genetics 152:1249-1267 doi

Church DN, Briggs SE, Palles C, Domingo E, Kearsey SJ, Grimes JM, Gorman M, Martin L, Howarth KM, Hodgson SV, Kaur K, Taylor J, Tomlinson IP, Collaborators N (2013) DNA polymerase $\varepsilon$ and $\delta$ exonuclease domain mutations in endometrial cancer. Hum Mol Genet 22:2820-2828. https://doi.org/10.1093/hmg/ddt131

Copeland WC (2010) The mitochondrial DNA polymerase in health and disease. Subcell Biochem 50:211-222. https://doi. org/10.1007/978-90-481-3471-7_11

Darmawan H, Harrison M, Reha-Krantz LJ (2015) DNA polymerase $3^{\prime} \rightarrow 5^{\prime}$ exonuclease activity: different roles of the beta hairpin structure in family-B DNA polymerases. DNA Repair 29:36-46. https://doi.org/10.1016/j.dnarep.2015.02.014

DeLano WL (2002) The PyMol molecular graphic system. DeLano Scientific, San Carlos, CA

Dmowski M, Fijałkowska IJ (2017) Diverse roles of Dpb2, the noncatalytic subunit of DNA polymerase $\varepsilon$. Curr Genet 63:983-987. https://doi.org/10.1007/s00294-017-0706-7

Doublie S, Zahn KE (2014) Structural insights into eukaryotic DNA replication. Front Microbiol. https://doi.org/10.3389/fmicb 2014.00444

Echols H, Goodman MF (1991) Fidelity mechanisms in DNA replication. Annu Rev Biochem 60:477-511. https://doi.org/10.1146/ annurev.bi.60.070191.002401

Edgell DR, Doolittle WF (1997) Archaea and the origin(s) of DNA replication proteins. Cell 89:995-998 doi 
Fernandez-Leiro R, Conrad J, Scheres SH, Lamers MH (2015) cryoEM structures of the E. coli replicative DNA polymerase reveal its dynamic interactions with the DNA sliding clamp, exonuclease and $\tau$. Elife. https://doi.org/10.7554/eLife.11134

Flood CL, Rodriguez GP, Bao GB, Shockley AH, Kow YW, Crouse GF (2015) Replicative DNA polymerase delta but not epsilon proofreads errors in cis and in trans. Plos Genet. https://doi. org/10.1371/journal.pgen.1005049

Franklin MC, Wang J, Steitz TA (2001) Structure of the replicating complex of a pol alpha family DNA polymerase. Cell 105:657667 doi

Ganai RA, Bylund GO, Johansson E (2015) Switching between polymerase and exonuclease sites in DNA polymerase $\varepsilon$. Nucleic Acids Res 43:932-942. https://doi.org/10.1093/nar/gku1353

Garbacz M, Araki H, Flis K, Bebenek A, Zawada AE, Jonczyk P, Makiela-Dzbenska K, Fijalkowska IJ (2015) Fidelity consequences of the impaired interaction between DNA polymerase epsilon and the GINS complex. DNA Repair 29:23-35. https ://doi.org/10.1016/j.dnarep.2015.02.007

Goldsby RE, Lawrence NA, Hays LE, Olmsted EA, Chen X, Singh M, Preston BD (2001) Defective DNA polymerase-delta proofreading causes cancer susceptibility in mice. Nat Med 7:638639. https://doi.org/10.1038/88963

Goldsby RE, Hays LE, Chen X, Olmsted EA, Slayton WB, Spangrude GJ, Preston BD (2002) High incidence of epithelial cancers in mice deficient for DNA polymerase delta proofreading. Proc Natl Acad Sci USA 99:15560-15565. https:// doi.org/10.1073/pnas.232340999

Goodman MF, Tippin B (2000) The expanding polymerase universe. Nat Rev Mol Cell Biol 1:101-109. https://doi. org/10.1038/35040051

Goodman MF, Creighton S, Bloom LB, Petruska J (1993) Biochemical basis of DNA replication fidelity. Crit Rev Biochem Mol Biol 28:83-126. https://doi.org/10.3109/10409239309086792

Gray MD, Shen JC, Kamath-Loeb AS, Blank A, Sopher BL, Martin GM, Oshima J, Loeb LA (1997) The Werner syndrome protein is a DNA helicase. Nat Genet 17:100-103. https://doi. org/10.1038/ng0997-100

Hashimoto H, Nishioka M, Fujiwara S, Takagi M, Imanaka T, Inoue T, Kai Y (2001) Crystal structure of DNA polymerase from hyperthermophilic archaeon Pyrococcus kodakaraensis KOD1. J Mol Biol 306:469-477. https://doi.org/10.1006/ jmbi.2000.4403

Hogg M, Johansson E (2012) DNA polymerase $\varepsilon$. Subcell Biochem 62:237-257. https://doi.org/10.1007/978-94-007-4572-8_13

Hogg M, Aller P, Konigsberg W, Wallace SS, Doublié S (2007) Structural and biochemical investigation of the role in proofreading of a beta hairpin loop found in the exonuclease domain of a replicative DNA polymerase of the B family. J Biol Chem 282:14321444. https://doi.org/10.1074/jbc.M605675200

Hogg M, Osterman P, Bylund GO, Ganai RA, Lundström EB, SauerEriksson AE, Johansson E (2014) Structural basis for processive DNA synthesis by yeast DNA polymerase $\varepsilon$. Nat Struct Mol Biol 21:49-55. https://doi.org/10.1038/nsmb.2712

Hollstein M, Shomer B, Greenblatt M, Soussi T, Hovig E, Montesano R, Harris CC (1996) Somatic point mutations in the p53 gene of human tumors and cell lines: updated compilation. Nucleic Acids Res 24:141-146 doi

Hopfner KP, Eichinger A, Engh RA, Laue F, Ankenbauer W, Huber R, Angerer B (1999) Crystal structure of a thermostable type B DNA polymerase from Thermococcus gorgonarius. Proc Natl Acad Sci USA 96:3600-3605 doi

Huang P (1998) Excision of mismatched nucleotides from DNA: a potential mechanism for enhancing DNA replication fidelity by the wild-type p53 protein. Oncogene 17:261-270. https://doi. org/10.1038/sj.onc.1201946
Johansson E, Macneill SA (2010) The eukaryotic replicative DNA polymerases take shape. Trends Biochem Sci 35:339-347. https ://doi.org/10.1016/j.tibs.2010.01.004

Johnson KA (1993) Conformational coupling in DNA polymerase fidelity. Annu Rev Biochem 62:685-713. https://doi.org/10.1146/ annurev.bi.62.070193.003345

Johnson KA (2010) The kinetic and chemical mechanism of highfidelity DNA polymerases. Biochim Et Biophys Acta Proteins Proteom 1804:1041-1048. https://doi.org/10.1016/j.bbapa p.2010.01.006

Johnson A, O'Donnell M (2005) Cellular DNA replicases: components and dynamics at the replication fork. Annu Rev Biochem 74:283-315. https://doi.org/10.1146/annurev.biochem.73.01130 3.073859

Joyce CM (1989) How DNA travels between the separate polymerase and 3'-5'-exonuclease sites of DNA polymerase I (Klenow fragment). J Biol Chem 264:10858-10866 doi

Kamath-Loeb AS, Shen JC, Loeb LA, Fry M (1998) Werner syndrome protein. II. Characterization of the integral $3^{\prime} \rightarrow 5^{\prime}$ DNA exonuclease. J Biol Chem 273:34145-34150 doi

Kamath-Loeb AS, Shen JC, Schmitt MW, Loeb LA (2012) The Werner syndrome exonuclease facilitates DNA degradation and high fidelity DNA polymerization by human DNA polymerase

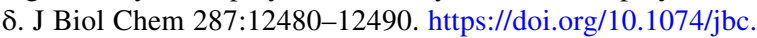
M111.332577

Kane DP, Shcherbakova PV (2014) A common cancer-associated DNA polymerase epsilon mutation causes an exceptionally strong mutator phenotype, indicating fidelity defects distinct from loss of proofreading. Can Res 74:1895-1901. https://doi. org/10.1158/0008-5472.can-13-2892

Karam JD, Konigsberg WH (2000) DNA polymerase of the T4-related bacteriophages. Prog Nucleic Acid Res Mol Biol 64:65-96

Kornberg A, Baker T (1992) DNA replication. W.H. Freeman, New York

Kunkel TA (2009) Evolving views of DNA replication (in)fidelity. Cold Spring Harb Symp Quant Biol 74:91-101. https://doi. org/10.1101/sqb.2009.74.027

Kunkel TA, Bebenek K (2000) DNA replication fidelity. Annu Rev Biochem 69:497-529. https://doi.org/10.1146/annurev.bioch em.69.1.497

Kunkel TA, Burgers PM (2008) Dividing the workload at a eukaryotic replication fork. Trends Cell Biol 18:521-527. https://doi. org/10.1016/i.tcb.2008.08.005

Kunkel TA, Hamatake RK, Motto-Fox J, Fitzgerald MP, Sugino A (1989) Fidelity of DNA polymerase I and the DNA polymerase I-DNA primase complex from Saccharomyces cerevisiae. Mol Cell Biol 9:4447-4458 doi

Lam WC, Van der Schans EJ, Joyce CM, Millar DP (1998) Effects of mutations on the partitioning of DNA substrates between the polymerase and $3^{\prime}-5^{\prime}$ exonuclease sites of DNA polymerase I (Klenow fragment). Biochemistry 37:1513-1522. https://doi. org/10.1021/bi9720181

Lamers MH, Georgescu RE, Lee SG, O’Donnell M, Kuriyan J (2006) Crystal structure of the catalytic alpha subunit of E. coli replicative DNA polymerase III. Cell 126:881-892. https://doi. org/10.1016/j.cell.2006.07.028

Lamichhane R, Berezhna SY, Gill JP, Van der Schans E, Millar DP (2013) Dynamics of site switching in DNA polymerase. J Am Chem Soc 135:4735-4742. https://doi.org/10.1021/ja311641b

Lee MYWT., Wang X, Zhang S, Zhang Z, Lee EYC (2017) Regulation and modulation of human DNA polymerase $\delta$ activity and function. Genes (Basel). https://doi.org/10.3390/genes8070190

Li V, Hogg M, Reha-Krantz LJ (2010) Identification of a new motif in family B DNA polymerases by mutational analyses of the bacteriophage t4 DNA polymerase. J Mol Biol 400:295-308. https:// doi.org/10.1016/j.jmb.2010.05.030 
Li F, Ball LG, Fan L, Hanna M, Xiao W (2017) Sgs1 helicase is required for efficient PCNA monoubiquitination and translesion DNA synthesis in Saccharomyces cerevisiae. Curr Genet. https ://doi.org/10.1007/s00294-017-0753-0

Liu S, Knafels JD, Chang JS, Waszak GA, Baldwin ET, Deibel MR, Thomsen DR, Homa FL, Wells PA, Tory MC, Poorman RA, Gao H, Qiu X, Seddon AP (2006) Crystal structure of the herpes simplex virus 1 DNA polymerase. J Biol Chem 281:18193-18200. https://doi.org/10.1074/jbc.M602414200

Makarova AV, Burgers PM (2015) Eukaryotic DNA polymerase $\zeta$. DNA Repair 29:47-55. https://doi.org/10.1016/j.dnare p.2015.02.012

Maki H, Kornberg A (1987) Proofreading by DNA polymerase III of Escherichia coli depends on cooperative interaction of the polymerase and exonuclease subunits. Proc Natl Acad Sci USA 84:4389-4392 doi

Mason PA, Cox LS (2012) The role of DNA exonucleases in protecting genome stability and their impact on ageing. Age (Dordr) 34:1317-1340. https://doi.org/10.1007/s11357-011-9306-5

McCulloch SD, Kunkel TA (2008) The fidelity of DNA synthesis by eukaryotic replicative and translesion synthesis polymerases. Cell Res 18:148-161. https://doi.org/10.1038/cr.2008.4

Melle C, Nasheuer HP (2002) Physical and functional interactions of the tumor suppressor protein p53 and DNA polymerase alphaprimase. Nucleic Acids Res 30:1493-1499 doi

Morrison A, Johnson AL, Johnston LH, Sugino A (1993) Pathway correcting DNA replication errors in Saccharomyces cerevisiae. EMBO J 12:1467-1473 doi

Mummenbrauer T, Janus F, Müller B, Wiesmüller L, Deppert W, Grosse F (1996) p53 Protein exhibits 3'-to-5' exonuclease activity. Cell 85:1089-1099 doi

Muzi-Falconi M, Giannattasio M, Foiani M, Plevani P (2003) The DNA polymerase alpha-primase complex: multiple functions and interactions. ScientificWorldJournal 3:21-33. https://doi. org/10.1100/tsw.2003.05

Network CGA (2012) Comprehensive molecular characterization of human colon and rectal cancer. Nature 487:330-337. https://doi. org/10.1038/nature 11252

Nishida H, Mayanagi K, Kiyonari S, Sato Y, Oyama T, Ishino Y, Morikawa K (2009) Structural determinant for switching between the polymerase and exonuclease modes in the PCNA-replicative DNA polymerase complex. Proc Natl Acad Sci USA 106:2069320698. https://doi.org/10.1073/pnas.0907780106

Ollis DL, Brick P, Hamlin R, Xuong NG, Steitz TA (1985) Structure of large fragment of Escherichia coli DNA polymerase I complexed with dTMP. Nature 313:762-766 doi

Park J, Jergic S, Jeon Y, Cho WK, Lee R, Dixon NE, Lee JB (2018) Dynamics of proofreading by the E. coli Pol III replicase. Cell Chem Biol 25:57-66.e54. https://doi.org/10.1016/j.chemb iol.2017.09.008

Patel PH, Suzuki M, Adman E, Shinkai A, Loeb LA (2001) Prokaryotic DNA polymerase I: evolution, structure, and "base flipping" mechanism for nucleotide selection. J Mol Biol 308:823-837. https://doi.org/10.1006/jmbi.2001.4619

Pavlov YI, Shcherbakova PV, Kunkel TA (2001) In vivo consequences of putative active site mutations in yeast DNA polymerases alpha, epsilon, delta, and zeta. Genetics 159:47-64 doi

Pavlov YI, Frahm C, Nick McElhinny SA, Niimi A, Suzuki M, Kunkel TA (2006) Evidence that errors made by DNA polymerase alpha are corrected by DNA polymerase delta. Curr Biol 16:202-207. https://doi.org/10.1016/j.cub.2005.12.002

Pellegrini L (2012) The Pol $\alpha$-primase complex. Subcell Biochem 62:157-169. https://doi.org/10.1007/978-94-007-4572-8_9

Perera RL, Torella R, Klinge S, Kilkenny ML, Maman JD, Pellegrini L (2013) Mechanism for priming DNA synthesis by yeast DNA polymerase $\alpha$. Elife 2:e00482. https://doi.org/10.7554/eLife .00482

Petrov VM, Ng SS, Karam JD (2002) Protein determinants of RNA binding by DNA polymerase of the T4-related bacteriophage RB69. J Biol Chem 277:33041-33048. https://doi.org/10.1074/ jbc.M204754200

Prindle MJ, Schmitt MW, Parmeggiani F, Loeb LA (2013) A substitution in the fingers domain of DNA Polymerase delta reduces fidelity by altering nucleotide discrimination in the catalytic site. J Biol Chem 288:5572-5580. https://doi.org/10.1074/jbc. M112.436410

Rayner E, van Gool IC, Palles C, Kearsey SE, Bosse T, Tomlinson I, Church DN (2016) A panoply of errors: polymerase proofreading domain mutations in cancer. Nat Rev Cancer 16:71-81. https:// doi.org/10.1038/nrc.2015.12

Reha-Krantz LJ (2010) DNA polymerase proofreading: Multiple roles maintain genome stability. Biochim Et Biophys Acta Proteins Proteom 1804:1049-1063. https://doi.org/10.1016/j.bbapa p.2009.06.012

Ren Z (2016) Molecular events during translocation and proofreading extracted from 200 static structures of DNA polymerase. Nucleic Acids Res 44:7457-7474. https://doi.org/10.1093/nar/gkw555

Rudd SG, Bianchi J, Doherty AJ (2014) PrimPol-A new polymerase on the block. Mol Cell Oncol 1:e960754. https://doi. org/10.4161/23723548.2014.960754

Salas M, Blanco L, Lázaro JM, de Vega M (2008) The bacteriophage phi29 DNA polymerase. IUBMB Life 60:82-85. https://doi. org/10.1002/iub.19

Savino C, Federici L, Johnson KA, Vallone B, Nastopoulos V, Rossi M, Pisani FM, Tsernoglou D (2004) Insights into DNA replication: the crystal structure of DNA polymerase B1 from the archaeon Sulfolobus solfataricus. Structure 12:2001-2008. https://doi. org/10.1016/j.str.2004.09.007

Schaaper RM (1993) Base selection, proofreading, and mismatch repair during DNA replication in Escherichia coli. J Biol Chem 268:23762-23765 doi

Scheuermann RH, Echols H (1984) A separate editing exonuclease for DNA replication: the epsilon subunit of Escherichia coli DNA polymerase III holoenzyme. Proc Natl Acad Sci USA 81:77477751 doi

Shamoo Y, Steitz TA (1999) Building a replisome from interacting pieces: sliding clamp complexed to a peptide from DNA polymerase and a polymerase editing complex. Cell 99:155-166 doi

Shcherbakova PV, Bebenek K, Kunkel TA (2003a) Functions of eukaryotic DNA polymerases. Sci Aging Knowl Environ 2003:RE3

Shcherbakova PV, Pavlov YI, Chilkova O, Rogozin IB, Johansson E, Kunkel TA (2003b) Unique error signature of the four-subunit yeast DNA polymerase epsilon. J Biol Chem 278:43770-43780. https://doi.org/10.1074/jbc.M306893200

Shlien A, Campbell BB, de Borja R, Alexandrov LB, Merico D, Wedge D, Van Loo P, Tarpey PS, Coupland P, Behjati S, Pollett A, Lipman T, Heidari A, Deshmukh S, Avitzur N, Meier B, Gerstung M, Hong Y, Merino DM, Ramakrishna M, Remke M, Arnold R, Panigrahi GB, Thakkar NP, Hodel KP, Henninger EE, Göksenin AY, Bakry D, Charames GS, Druker H, Lerner-Ellis J, Mistry M, Dvir R, Grant R, Elhasid R, Farah R, Taylor GP, Nathan PC, Alexander S, Ben-Shachar S, Ling SC, Gallinger S, Constantini S, Dirks P, Huang A, Scherer SW, Grundy RG, Durno C, Aronson M, Gartner A, Meyn MS, Taylor MD, Pursell ZF, Pearson CE, Malkin D, Futreal PA, Stratton MR, Bouffet E, Hawkins C, Campbell PJ, Tabori U, Consortium BMRD. (2015) Combined hereditary and somatic mutations of replication error repair genes result in rapid onset of ultra-hypermutated cancers. Nat Genet 47:257-262. https://doi.org/10.1038/ng.3202 
Showalter AK, Tsai MD (2002) A reexamination of the nucleotide incorporation fidelity of DNA polymerases. Biochemistry 41:10571-10576 doi

St Charles JA, Liberti SE, Williams JS, Lujan SA, Kunkel TA (2015) Quantifying the contributions of base selectivity, proofreading and mismatch repair to nuclear DNA replication in Saccharomyces cerevisiae. DNA Repair 31:41-51. https://doi.org/10.1016/j. dnarep.2015.04.006

Stano NM, Chen J, McHenry CS (2006) A coproofreading Zn(2+)dependent exonuclease within a bacterial replicase. Nat Struct Mol Biol 13:458-459. https://doi.org/10.1038/nsmb1078

Steitz TA (1999) DNA polymerases: structural diversity and common mechanisms. J Biol Chem 274:17395-17398. https://doi. org/10.1074/jbc.274.25.17395

Subuddhi U, Hogg M, Reha-Krantz LJ (2008) Use of 2-aminopurine fluorescence to study the role of the beta hairpin in the proofreading pathway catalyzed by the phage T4 and RB69 DNA polymerases. Biochemistry 47:6130-6137. https://doi.org/10.1021/ bi800211f

Swan MK, Johnson RE, Prakash L, Prakash S, Aggarwal AK (2009) Structural basis of high-fidelity DNA synthesis by yeast DNA polymerase delta. Nat Struct Mol Biol 16:979-986. https://doi. org/10.1038/nsmb.1663

Sweasy JB, Lauper JM, Eckert KA (2006) DNA polymerases and human diseases. Radiat Res 166:693-714. https://doi. org/10.1667/RR0706.1

Szwajczak E, Fijalkowska IJ, Suski C (2017) The importance of an interaction network for proper DNA polymerase $\zeta$ heterotetramer activity. Curr Genet. https://doi.org/10.1007/s00294-017-0789-1

Tahirov TH (2012) Structure and function of eukaryotic DNA polymerase $\delta$. Subcell Biochem 62:217-236. https://doi. org/10.1007/978-94-007-4572-8_12

Toste Rêgo A, Holding AN, Kent H, Lamers MH (2013) Architecture of the Pol III-clamp-exonuclease complex reveals key roles of the exonuclease subunit in processive DNA synthesis and repair. EMBO J 32:1334-1343. https://doi.org/10.1038/emboj.2013.68
Trzemecka A, Płochocka D, Bebenek A (2009) Different behaviors in vivo of mutations in the beta hairpin loop of the DNA polymerases of the closely related phages T4 and RB69. J Mol Biol 389:797-807. https://doi.org/10.1016/j.jmb.2009.04.055

Wang F, Yang W (2009) Structural insight into translesion synthesis by DNA Pol II. Cell 139:1279-1289. https://doi.org/10.1016/j. cell.2009.11.043

Wang J, Sattar AK, Wang CC, Karam JD, Konigsberg WH, Steitz TA (1997) Crystal structure of a pol alpha family replication DNA polymerase from bacteriophage RB69. Cell 89:1087-1099 doi

Wang M, Xia S, Blaha G, Steitz TA, Konigsberg WH, Wang J (2011) Insights into base selectivity from the $1.8 \AA$ resolution structure of an RB69 DNA polymerase ternary complex. Biochemistry 50:581-590. https://doi.org/10.1021/bi101192f

Xia S, Konigsberg WH (2014) RB69 DNA polymerase structure, kinetics, and fidelity. Biochemistry 53:2752-2767. https://doi. org/10.1021/bi4014215

Xu X, Yan C, Kossmann BR, Ivanov I (2016) Secondary interaction interfaces with PCNA control conformational switching of DNA polymerase PolB from polymerization to editing. J Phys Chem B 120:8379-8388. https://doi.org/10.1021/acs.jpcb.6b02082

Yamamoto H, Imai K (2015) Microsatellite instability: an update. Arch Toxicol 89:899-921. https://doi.org/10.1007/s00204-015-1474-0

Yang J, Zhuang Z, Roccasecca RM, Trakselis MA, Benkovic SJ (2004) The dynamic processivity of the T4 DNA polymerase during replication. Proc Natl Acad Sci USA 101:8289-8294. https:// doi.org/10.1073/pnas.0402625101

Yang W, Weng PJ, Gao Y (2016) A new paradigm of DNA synthesis: three-metal-ion catalysis. Cell Biosci 6:51. https://doi. org/10.1186/s13578-016-0118-2

Zhang Q, Chen H, Chen Y, Zhou Y (2016) Multiple forms of human DNA polymerase delta sub-assembling in cellular DNA transactions. Curr Protein Pept Sci 17:746-755 doi

Zhao L, Washington MT (2017) Translesion synthesis: insights into the selection and switching of DNA polymerases. Genes (Basel) https://doi.org/10.3390/genes8010024 